\title{
Os Crimes financeiros à Luz dos Princípios CONSTITUCIONAIS BRASILEIROS
}

MiLton Fornazari JUNior

Departamento de Polícia Federal - Brasil

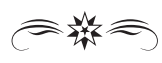

\section{RESUMO}

O presente artigo trata da definição e dos conceitos dos princípios constitucionais penais e princípios influentes em matéria penal, bem como sua aplicação aos crimes financeiros, à luz da Constituição Federal de 1988.

Palavras-Chave: Crimes financeiros. Princípios constitucionais.

\section{INTRODUÇÃ̃o}

O presente estudo visa identificar a existência dos princípios constitucionais em matéria penal, tanto para fundamentar a punição nos crimes financeiros, bem como para delimitar a atuação estatal frente aos direitos individuais.

Nesse sentido, é proposta ao longo do presente artigo uma releitura dos princípios constitucionais penais, a fim de assegurar a sua observância pelo legislador e pelo Estado, mas também visando garantir a todos o direito à segurança, por meio de normas aptas e eficazes a combater os autores de crimes financeiros, caracterizados pela complexidade da conduta típica.

\section{A Constituição federal e os Crimes Financeiros}

A Constituição Federal de 1988, assim como a maioria das constituições contemporâneas do mundo ocidental, buscou conciliar os ideais iluministas do Estado Liberal com os preceitos sociais do Es- 
tado Social de Direito, consagrando assim uma nova forma de Estado, o Estado Democrático de Direito. ${ }^{1}$

Na precisa lição de Luiz Luisi:

"ao incorporar os princípios do Estado liberal e do Estado social, e ao conciliá-los, as Constituiçóes modernas, renovam de um lado, as garantias individuais, mas por outro lado introduzem uma série de normas destinadas a tornar concretas, ou seja, 'reais', a liberdade e a igualdade dos cidadãos, tutelando valores de interesse geral como os pertinentes ao trabalho, a saúde, a assistência social, a atividade econômica, o meio ambiente, a educação, a cultura etc." (LUISI, 2003, p. 12).

Desta maneira, na Constituição Federal de 1988 convivem e devem conviver em harmonia os princípios que expressam os direitos e as garantias individuais e os princípios de proteção de valores supraindividuais e da justiça social.

Quanto aos princípios penais constitucionais, Luiz Luisi ensina que em nossa atual Constituição existem duas espécies: a) os princípios de direito penal constitucional; e b) os princípios constitucionais influentes em matéria penal. (LUISI, 2003, p. 13).

Os primeiros são aqueles que carregam exclusiva matéria penal e que, na maioria das vezes, consagram direitos e garantias individuais, como o princípio da legalidade dos crimes e das penas, o princípio da pessoalidade da pena, da intervenção mínima do direito penal, da individualização da pena, da humanidade e da culpabilidade. Esses princípios visam instituir de maneira direta e imediata uma garantia aos cidadãos. (CANOTILHO, 2000, p. 1168).

Os princípios influentes em matéria penal não têm conteúdo tipicamente penal. Dispõem sobre o conteúdo das incriminações. São eles que dão ao Direito Penal a função de ser mais um instrumento do Estado na tutela de bens de relevância social. Consistem, em geral, como fonte e vínculo ao legislador infraconstitucional, no sentido de orientar a elaboração de normas penais incriminadoras, destinadas à proteção dos valores constitucionais supraindividuais.

1 Constituição Federal: "Art. 1 A República Federativa do Brasil, formada pela união indissolúvel dos Estados e Municípios e do Distrito Federal, constitui-se em Estado Democrático de Direito e tem como fundamentos: (...)." 
Exemplos desses valores constitucionalmente protegidos são a ordem econômica, o sistema financeiro nacional, o meio ambiente, o consumo, a saúde, a ordem tributária, a cultura, a pesquisa científica etc.

Assim, os atentados de maior gravidade contra esses interesses são eleitos pelo legislador como crimes e sujeitos à sanção penal.

Para o presente estudo ressaltamos o crime financeiro, compreendido como aquele que consubstancia uma conduta que tenha o sério potencial de atingir um interesse constitucionalmente protegido, um bem de natureza supraindividual, relacionado diretamente ao sistema financeiro nacional, bem de extrema relevância social, na medida em que a Constituição, em seu artigo 192, determina que o sistema financeiro deve ser estruturado com a finalidade de promover o desenvolvimento equilibrado do País.

Atualmente, os crimes financeiros estão previstos na Lei $\mathrm{n}^{\circ}$ 7.492/86 (Lei dos Crimes Contra o Colarinho Branco) e, também, nos artigos 27-C a 27-E, da Lei no 6.385/76, referente aos crimes contra o Mercado de Capitais.

Para atingir os fins do sistema financeiro nacional, o legislador deverá editar normas que contenham sançôes a todas as condutas ofensivas. Essas normas podem ter natureza civil (pena de indenização), natureza administrativa (sanção de multa) ou, se necessário, natureza de normas penais incriminadoras. (LUISI, 2003, p. 14).

No Estado Democrático de Direito, portanto, os princípios de direito penal constitucional e os princípios constitucionais influentes em matéria penal são os fundamentos do direito de punir do Estado e, também, elevam o Direito Penal à nobre missão de ser um instrumento para a consecução de uma sociedade mais justa, que atenda plenamente as diretrizes constitucionais.

Para cumprir essa missão, em especial no sistema financeiro nacional, os princípios constitucionais penais são aplicados nos crimes financeiros com algumas particularidades, uma vez que a velocidade com que operam as relaçóes econômicas e financeiras é muito maior que a das relações jurídicas. 
De fato, na elaboração de tipos penais financeiros, é conveniente a utilização de técnicas legislativas que permitam uma maior rapidez da resposta penal (FIGUEIREDO DIAS; COSTA ANDRADE, 2001, p. 90), como, por exemplo, a norma penal em branco, técnica utilizada nos crimes de evasão de divisas e outros crimes previstos na Lei ${ }^{\circ}$ 7.492/86, dentre outros.

Passamos, a seguir, a analisar os tradicionais princípios constitucionais de direito penal e as suas particularidades na incidência sobre os delitos financeiros.

\section{Princípio da Legalidade}

O princípio da legalidade está previsto no artigo $5^{\circ}$, inciso XXXIV e XL, da Constituição Federal, enunciado nos seguintes termos: "não há crime sem lei anterior que o defina, nem pena sem prévia cominação legal"; “a lei penal não retroagirá, salvo para beneficiar o réu".

Desta forma, nenhum fato pode ser considerado como crime e nenhuma sanção penal pode ser aplicada, sem que antes da ocorrência do fato tenham sido instituídos por lei o tipo penal e a pena respectiva, o que constitui uma limitação ao Estado de interferir na esfera das liberdades individuais da pessoa humana. (TOLEDO, 1994, p. 21).

O princípio da legalidade tem sua origem, segundo a maioria da Doutrina, na Magna Charta Libertatum, editada pelo Rei João Sem Terra na Inglaterra, em 1215.

Posteriormente, foi consagrado no Bill of Rights das colônias inglesas situadas no que viria a ser os Estados Unidos da América, e, também, na Declaração Francesa dos Direitos do Homem e do Cidadão de 1789, de onde se espalhou para os demais países do mundo ocidental.

A formulação de seu enunciado em latim: "nullum crime e nulla poena sine previa lege", como é conhecida hoje, deve-se ao alemão Anselm Von Ferbeauch, em seu tratado de Direito Penal, de 1801. (BATISTA, 1996, p. 66).

Seu conteúdo é inspirado pelas idéias do Iluminismo, movimento político do século XVIII, ao qual pertenceram Rousseau, Voltaire e 
Bonesana, e visa proibir a criação de condutas incriminadoras e penas, sem a anterior edição de lei elaborada por um órgão constitucionalmente competente. Com ele, permite-se aos particulares a certeza de que somente será vedado fazer ou deixar de fazer algo (e com isso incorrer em sanções penais) se tal fato estiver descrito em lei.

O fundamento do princípio da legalidade é a dignidade da pessoa humana, pois assim se reconhece que há direitos inerentes à pessoa humana, que não precisam e não são outorgados pelo Estado. Por outro lado, em razão de o Estado deter o poder e dever de estabelecer certas limitações e proibições para o pleno desenvolvimento da pessoa humana no meio social, tais proibições casuísticas devem ocorrer, exclusivamente, por meio de lei. (TOLEDO, 1994, p. 22).

O princípio da legalidade, além de assegurar a exigência de lei e de sua anterioridade, também garante a proibição da incriminação de condutas por termos vagos ou indeterminados (princípio da taxatividade - lex certa), vedação da retroatividade da lei penal que prejudique o réu (lex praevia) e, ainda, a criação de crimes e penas pelo costume ou pela analogia (lex scripta e stricta). (TOLEDO, 1994, p. 23-29).

Mas, o princípio da legalidade não pode ser visto apenas como garantia de criação de tipos penais por lei em sentido formal.

Com efeito, para que o Direito Penal seja um direito justo e democrático, é preciso que o princípio da legalidade tenha um aspecto material, destinado a evitar que o Poder Legislativo empregue à produção de leis o conteúdo que quiser. (CARVALHO, 1992, p. 56).

Esse aspecto material do princípio da legalidade se traduz pela informação do conteúdo da lei penal pelos valores constitucionais. Isto quer dizer que os tipos penais devem visar a proteção da forma mais eficiente possível de bens jurídicos que reflitam os princípios constitucionais.

A Constituição Federal de 1988 expressou princípios conquistados no desenvolvimento de nosso processo histórico e, por isso, devem eles se realizar por todos os instrumentos do Direito, inclusive o Direito Penal e o seu específico princípio da legalidade. (CARVALHO, 1992, p. 57). 
Conclui-se que o princípio da legalidade compatibiliza-se como Estado Democrático de Direito (Artigo $1^{\circ}$, da Constituição Federal), na medida em que submeta o legislador à realização dos fins e princípios constitucionais.

Nos itens 3.1, 3.2 e 3.3, veremos as peculiaridades de sua aplicação em relação aos crimes financeiros.

\section{I. PRINCÍPIO DA ANTERIORIDADE (LEX PRAEVIA)}

O princípio da anterioridade da lei penal, de acordo com o artigo $5^{\circ}$, incisos XXXIV e XL, da Constituição Federal, exige que a lei instituidora do crime e da pena seja anterior à prática do fato que se pretende punir. (TOLEDO, 1994, p. 23).

Desta maneira, o princípio da anterioridade se desdobra em duas exigências. A primeira é que a edição da lei seja anterior ao fato e a segunda é que a lei penal não retroagirá,a não ser em favor do réu.

O princípio da anterioridade assegura ao cidadão, a segurança de não ser punido, ou de não ser punido mais severamente, por fatos que no momento de sua ocorrência, não eram sancionados pelo Direito Penal, ou o eram de forma mais benéfica. (LUISI, 2003, p. 26).

A exigência da anterioridade da lei, assim como os demais princípios constitucionais penais, espalhou-se pelas Constituições do mundo ocidental, após a Declaração Francesa dos Direitos do Homem e do Cidadão de 1789.

No Brasil, entretanto, o princípio da anterioridade só teve previsão expressa pela primeira vez na Constituição Federal de 1934, em seu artigo 113, inciso XXVII.

Posteriormente, o princípio foi abrigado por todas as Constituições que se seguiram, mas nem sempre a legislação infraconstitucional o respeitou.

Com efeito, no Brasil, em 1942, foi editada a Lei n $4.766 / 42$, que determinou a retroatividade da sanção penal nos crimes nela previstos às situações de fato anteriores à sua edição, até a data da ruptura das 
relações diplomáticas com a Alemanha, Japão e Itália, durante a eclosão da Segunda Guerra Mundial.

Tirante essa exceção, o princípio da anterioridade vige plenamente em nosso País, não se registrando ofensas em sua aplicação.

Em relação à anterioridade da lei penal, não há que se falar em exceção ou mitigação deste princípio nos chamados crimes financeiros, devendo a norma penal ter sua vigência determinada em data anterior ao fato, seja ela norma penal em branco ou não.

\subsection{O PRINCÍPIO DA IRRETROATIVIDADE E AS NORMAS PENAIS EM BRANCO}

O princípio da irretroatividade da lei penal também é corolário do princípio da legalidade e sub-espécie do princípio da anterioridade. Está expressamente previsto no artigo $5^{\circ}$, inciso XL, da Constituição Federal, nos seguintes termos: "a lei penal não retroagirá, salvo para beneficiar o réu".

Este princípio expressa a exigência de que a lei penal seja atual, ou seja, que só alcance os fatos cometidos após a sua vigência, na tipificação de crimes ou quando majore penas dos crimes já existentes à época do fato.

Entrementes, o artigo $3^{\circ}$ do Código Penal prevê a ultratividade das leis penais excepcionais e temporárias, aplicando-se a sanção penal ao fato praticado durante a sua vigência, mesmo que aquelas já tenham saído do ordenamento.

$\mathrm{Na}$ hipótese de lei excepcional, trata-se de aplicação retroativa, pois a sua aplicação pode ocorrer após decorrido o prazo de sua eficácia.

Cabe examinarmos, então, se as leis que incriminam condutas lesivas à ordem econômica podem ser consideradas leis excepcionais.

Entendemos que a resposta é positiva, pois as normas que disciplinam a política econômica são extremamente mutáveis, uma vez que variam segundo as conjunturas político-econômicas verificadas no País e no mundo. Assim, as normas integradoras dos crimes financeiros possuem a característica da mutabilidade, já que se relacionam diretamente 
com a situação econômica do País, tendo assim um caráter meramente conjuntural e só podem ser entendidas como normas de caráter excepcional. (FELDENS, 2002, p. 157).

Para que o princípio da retroatividade mais benéfica seja aplicado à norma penal em branco é necessário que a alteração legislativa atinja a própria norma penal básica, pois se a mudança atingir a norma complementar não há possibilidade do reconhecimento retroativo ao agente. ${ }^{2}$

Nesse sentido, também já decidiu o Supremo Tribunal Federal em relação aos crimes contra a ordem econômica. ${ }^{3}$

\subsection{O PRINCÍPIO DA TAXATIVIDADE E AS NORMAS PENAIS EM BRANCO}

A lei penal deve ser certa. Este é o enunciado do princípio da taxatividade, corolário do princípio da legalidade. Com isso se quer dizer que a norma penal deve determinar com suficiente precisão o fato criminoso. O crime financeiro não pode consistir numa situação, qualidade ou atitude pessoal. O fato, ação ou omissão, não pode ser deduzido da lei, mas sim estar descrito nela. Para que a garantia da legalidade seja respeitada, é necessário que a descrição do fato delituoso seja suficientemente clara e unívoca. (SILVA, 2010, p. 228).

Ocorre que nos crimes financeiros é comum o uso das chamadas normas penais em branco, a exemplo dos artigos $10^{4}$ e 22, da Lei ${ }^{\circ}$ 7.492/86, dentre outros.

E a norma penal em branco nada mais é do que a norma que estabelece uma pena para uma conduta que está individualizada em outra norma.

São chamadas homogêneas as normas que têm o seu complemento em outras leis editadas pelo órgão constitucional competente, ou seja, em diplomas normativos da mesma natureza e hierarquia. As normas pe-

2 TRF 4a Região, RT 790/2001.

3 STF, RT 556/425.

4 "Artigo 10. Fazer inserir elemento falso ou omitir elemento exigido pela legislação, em demonstrativos contábeis de instituição financeira, seguradora ou instituição integrante do sistema de distribuição de títulos de valores mobiliários: Pena - reclusão de 1 (um) a 5 (cinco) anos." 
nais em branco heterogêneas, por sua vez, são integradas por diplomas legislativos inferiores (Resoluções, Portarias, Circulares etc.), geralmente editados pelo Poder Executivo.

Parte da Doutrina entende que a norma penal em branco é inconstitucional porque feriria o princípio da legalidade. ${ }^{5}$

No entanto, o emprego desta técnica legislativa deve ser aceito quando necessária em razão do caráter extraordinariamente mutável da matéria objeto de regulação, que exigiria uma revisão freqüente das ações proibidas ou ordenadas, tornando ineficaz a tutela penal. (CEREZO MIR, 1997, p. 156).

Demais disso, deve se atentar para que o princípio da legalidade não seja interpretado como garantia absoluta, sob pena de obstaculizar a realização das diretrizes impostas em preceitos constitucionais, especialmente as da ordem econômica e do sistema financeiro nacional, o que nos levaria de volta aos primórdios do Estado meramente liberal.

Cabe ressaltar que os princípios da ordem econômica, no Estado Democrático de Direito, também se destinam ao legislador penal, a quem cabe encontrar a melhor maneira de tutelar esses valores, dada a velocidade com que opera a economia e a necessidade de mudanças drásticas do Estado na condução de sua política econômica global, a fim de evitar sérios danos ao país.

Por outro lado, o princípio da legalidade, como conquista histórica de liberdade frente ao Estado, não pode ser aniquilado para a proteção da ordem econômica. Dito isto, é preciso encontrar um equilíbrio no uso dessa técnica legislativa.

Assim, quando a norma que há de completar a lei penal em branco tiver caráter delegado, o legislador deve prever o "núcleo essencial da proibição", ou seja, a sanção aplicável e a descrição do conteúdo, da finalidade e do alcance da autorização para que o cidadão possa extrair já na lei os pressupostos da punibilidade e a classe de pena, pois, do contrário, não se respeitaria o princípio da determinação legal do delito e da pena. (JESCHECK, 1993, p. 98).

5 Nesse sentido: Luiz Luisi, op. cit., p. 125 e Rogério Greco. Curso de Direito Penal - Parte Geral. 2a edição. Rio de Janeiro: Impetus, 2003, p. 27. 
Com a previsão do núcleo essencial da proibição, deixando para a norma integradora apenas questões de detalhe, a delegação não transfere ao poder executivo os limites do fato típico, pelo contrário, restringe o âmbito do que já é proibido.

Dessa maneira, entendemos compatíveis com o princípio da legalidade o uso das normas penais em branco, tanto nos delitos comuns, como nos delitos financeiros (a fortiori), desde que estabelecidos os seguintes requisitos: a) que a remissão esteja justificada em razão do bem jurídico protegido pela norma penal; b) que a norma já preveja a sanção penal no seu preceito secundário; e c) que o preceito primário contenha o "núcleo essencial da proibição".

Se necessário, no caso concreto, verificada demasiada abertura na norma penal em branco, ainda assim se poderá corrigir o uso dela por meio da interpretação restritiva que informa todas as normas penais. ${ }^{7}$

\section{Princípio da Culpabilidade}

O princípio da culpabilidade é um princípio penal constitucional previsto em quase todas as Constituições contemporâneas do mundo ocidental.

A Constituição Federal de 1988 albergou este princípio no artigo 5०, inciso XVII: "ninguém será culpado até o trânsito em julgado de sentença penal condenatória." E também, implicitamente, no inciso XLVI, do mesmo artigo, que trata da individualização da pena.

Segundo Assis Toledo, deve-se entender o princípio da culpabilidade como "a exigência de um juízo de reprovação jurídica que se apóia sobre a crença - fundada na experiência cotidiana da vida - de que ao homem é dada a possibilidade de, em certas circunstâncias, 'agir de outro modo'”. (TOLEDO, 1994, p. 86).

6 Recomendação no 8, do XIII Congresso Internacional de Direito Penal, realizado no Cairo, em 1984, dois anos antes da edição da Lei no 7.492/86: "Em relação à descrição dos crimes, o emprego de técnicas de remissão a instâncias normativas externas ao direito penal, para determinar quais sejam as condutas incriminadas, pode levar aos perigos da imprecisão e da falta de clareza, bem como a um excesso de delegação do Poder Legislativo à Administração. A conduta ou o resultado devem estar especificados, na medida do possível, no próprio preceito penal”.

7 Nesse sentido: TIEDEMANN, Klaus. "La Ley Penal em Blanco: concepto y cuestiones conexas". In Revista Brasileira de Ciências Criminais, São Paulo: RT, jan./mar. 2002, vol. 37, p. 77. 
O princípio da culpabilidade tem dupla finalidade: impede a responsabilidade objetiva do agente e, também, funciona como pressuposto da sanção penal ao criminoso que pratica um fato típico e antijurídico, ou seja, é por esse princípio que se "conecta" o agente ao crime.

O fundamento maior do princípio da culpabilidade é a dignidade da pessoa humana, que põe o ser humano como centro do Direito Penal, visto como um ser livre, plenamente capaz de se autodeterminar dentro do meio social. (LUISI, 2003, p. 38).

Com essa dimensão ética dada pela dignidade da pessoa humana, o princípio da culpabilidade deve ser revisto para auxiliar na consecução de uma sociedade mais justa, onde as pessoas tenham igualdade de acesso às oportunidades sociais.

A dogmática jurídica não pode ignorar a integração do direito em formações sociais determinadas. $\mathrm{O}$ dogma da culpabilidade, quando da sua concretização não se deve medir da mesma forma para um infrator de crimes patrimoniais, que teve negado, seja pelo Estado, seja pelas camadas mais ricas da sociedade, os direitos sociais necessários ao seu pleno desenvolvimento (artigo $6^{\circ}$ da Constituição Federal ${ }^{8}$ ), e para um infrator sócio-finaceiramente bem situado, que nunca sofreu carência resultante da não fruição dos direitos sociais. (CARVALHO, 1992, p. 72).

Os criminosos que atacam os bens vinculados ao sistema financeiro nacional, via de regra, vivem de forma abastada e se enquadram na espécie de infrator economicamente bem sucedido. (SUTHERLAND, 1949).

Por isso, a culpabilidade nos crimes financeiros é muitas vezes artificial, o que não se confunde com a responsabilidade objetiva, que configura responsabilidade penal do agente, sem que este tenha agido com culpa, e está banida do nosso ordenamento jurídico.

A culpabilidade artificial pertence ao chamado Direito Penal Secundário, que sanciona com penas, violações próprias do Direito Adminis-

8 "Art. $6^{\circ}$ São direitos sociais a educação, a saúde, o trabalho, a moradia, o lazer, a segurança, a previdência social, a proteção à maternidade e à infância, a assistência aos desamparados, na forma desta Constituição." 
trativo (FIGUEIREDO DIAS, 2001, p. 14-15), motivo pelo qual a sanção penal aplicada tem como finalidade a construção de uma ética social, até então não existente.

Com efeito, as normas que regulam o sistema financeiro nacional não se fundamentam, via de regra, sobre normas de valoração cultural pré-existentes, interiorizadas e atuantes na consciência coletiva. Por isso, não costuma ocorrer uma reação espontânea da comunidade (com estigma e distância social) aos criminosos, que muitas vezes são tratados como os símbolos do sucesso e, por isso mesmo, da própria virtude. (FARIA COSTA; COSTA ANDRADE, 2001, p. 101).

Assim, a necessidade dessa forma de tutela penal parece inquestionável quando se trata de crimes financeiros.

A compatibilidade da artificialidade desses delitos com o princípio da culpabilidade se verifica com a exigência de que as normas, que dão o rumo da política econômica, estejam em consonância com as diretrizes e os princípios constitucionais da ordem econômica e de toda a Constituição Federal.

Com efeito, convém destacar que o sistema financeiro nacional é regulado dentro do Título VII da Constituição Federal, referente aos princípios da ordem econômica e social.

\section{Princípio da InSignificânCia}

O princípio da insignificância está ligado à tipicidade penal e recomenda que o Direito Penal somente intervenha nas hipóteses de séria lesão aos bens jurídicos penalmente protegidos, deixando de lado as lesões demasiadamente leves, insignificantes.

A Declaração Francesa dos Direitos do Homem e do Cidadão de 1789 , em seu artigo $8^{\circ}$, estabeleceu que "a lei apenas deve estabelecer penas estrita e devidamente necessárias”, consagrando a intervenção mínima do Direito Penal, a sua fragmentariedade e o princípio da insignificância.

Isso quer dizer que não basta à lei penal descrever uma conduta proibida, mas que o legislador deve primeiro selecionar os bens mais im- 
portantes existentes no meio social para a proteção penal, que no caso dos crimes financeiros é o sistema financeiro nacional.

Ainda na fase da seleção dos bens a serem protegidos pelo Direito Penal, deve o legislador observar as condutas socialmente adequadas e afastá-las da incidência do tipo penal.

Assim, ao redigir o tipo penal, o legislador somente terá como finalidade evitar os prejuízos relevantes que possam advir de um comportamento ilícito em ataque a um bem jurídico.

Entretanto, não tem ele, legislador, meios para impedir que também sejam punidos os prejuízos leves, insignificantes. (GRECO, 2003, p. 71).

Cabe ao intérprete, por meio do princípio da insignificância, excluir da subsunção penal as situações consideradas como de "bagatela”.

Dessa maneira, considerados o princípio da intervenção penal mínima do Estado (dirigido ao legislador) e o princípio da insignificância (dirigido ao intérprete), cumpre reconhecer que o direito penal não se deve ocupar de condutas que produzam resultado, cujo desvalor - por não importar em lesão significativa a bens jurídicos relevantes - não represente, por isso mesmo, prejuízo importante ao bem jurídico penalmente protegido. (DOTTI, 2004, p. 68).

A Constituição Federal agasalha este princípio implicitamente, uma vez que dispõe que os direitos e garantias individuais nela previstos não excluem outros decorrentes do regime e dos princípios por ela adotados 9 . Ora, não se pode deixar de reconhecer que o princípio em questão se encontra vinculado com outros princípios explícitos da Constituição Federal (legalidade, culpabilidade, devido processo legal etc.), bem como com os fundamentos do Estado Democrático de Direito. (LUISI, 2003, p. 39).

Todavia, para o reconhecimento da exclusão da tipicidade por esse princípio, já decidiu o Supremo Tribunal Federal ser necessário a presença dos seguintes requisitos: (a) a mínima ofensividade da conduta do agente; (b) a nenhuma periculosidade social da ação; (c) o reduzidíssi-

9 Constituição Federal: artigo $5^{\circ}, \$ 2^{\circ}$. 
mo grau de reprovabilidade do comportamento; e (d) a inexpressividade da lesão jurídica provocada. ${ }^{10}$

Nos crimes financeiros que possuem em seu tipo penal o emprego das normas penais em branco, o princípio da insignificância deve ser afastado porque a lei extrapenal sempre deve definir precisamente e pormenorizadamente os limites da conduta.

Por exemplo, no crime de evasão de divisas a legislação administrativa já pró́be a saída de valores acima de $\mathrm{R} \$ 10.000,00$ em desacordo com as normas cambiais. Assim, aquele que não observar esse mandamento não poderá argüir o princípio da insignificância para evitar a sanção penal, uma vez que os valores permitidos e proibidos já estão previamente definidos pela legislação.

Por outro lado, em razão do bem jurídico penalmente protegido, qual seja, o sistema financeiro nacional (de extrema relevância para a vida em sociedade), é difícil se imaginar que possa uma ação contrária a ele não conter uma relevante carga de periculosidade social.

Por fim, acreditamos que em razão da artificialidade dos crimes financeiros, o princípio da insignificância também não pode ser aplicado apenas com base no reduzidíssimo grau de reprovabilidade do comportamento, sob pena de frustrar o ideal de justiça.

\section{Princípio do "Ne Bis IN IDEM"}

O Princípio do Ne Bis In Idem, embora não esteja expressamente previsto na Constituição, é facilmente deduzido do regime democrático e do princípio da dignidade da pessoa humana que estão a informar a sua existência.

O princípio em estudo possui duplo significado. No Direito Penal veda a imposição de duas penas em face do mesmo crime, enquanto no Direito Processual Penal pró́be que alguém seja processado e julgado mais de uma vez pelo mesmo fato.

10 STF - 2a Turma - HC 84.412/SP - Rel. Min. Celso de Mello. DJU: 19/11/2004, p. 37. 
Não verificamos nenhuma incompatibilidade da aplicação deste princípio aos crimes financeiros.

O que se costuma confundir nos crimes financeiros é a distinção de ato e crime. Como é sabido, um agente pode praticar em concurso formal mais de um crime mediante um só ato ou omissão, devendo responder pela pena mais grave ou, se iguais, somente a uma delas, desde que aumentada de um sexto até metade. ${ }^{11}$

Por exemplo, é comum a prática da sonegação tributária e da evasão de divisas com um único ato de promoção de saída de dinheiro do País. Há dois crimes pelos quais o agente deverá responder, exasperando-se a pena mais grave.

De fato, no exemplo citado, há dois bens jurídicos distintos atingidos (a política fiscal no caso da sonegação e a política cambial na evasão). Essa exasperação, determinada pelo Código Penal (art. 70), não se configura exceção e é plenamente compatível com o postulado do "ne bis in idem".

\section{Conclusã̃o}

Como se depreende do presente estudo, o combate aos crimes financeiros está fundamentado nos princípios constitucionais influentes em matéria penal, previstos na Constituição Federal brasileira, bem como encontram seus limites nos princípios constitucionais penais.

Demais disso, verifica-se que a técnica legislativa da norma penal em branco é uma das medidas capazes de imprimir maior eficiência no combate a essa espécie de crimes.

MILTON FORNAZARI JUNIOR

Delegado de Polícia Federal, na Delegacia de Repressão a Crimes Financeiros e Desvio de Recursos Públicos em São Paulo, Mestre em Direito Penal e Doutorando em Direito Processual Penal pela PUC/SP. E-MAIL:MILTON.MFJ@DPF.GOV.BR

11 Artigo 70, do Código Penal. 


\section{ABSTRACT}

Financial Crime in the light of the Brazilian Constitutional Principles

This paper deals about the definition and concepts of criminal constitutional principles and influential principles in criminal matters, as well as its applications to financial crimes in the light of the Constituição Federal de 1988

KEYwORDS: Financial Crimes; Constitutional Principles

\section{REFERÊNCIAS}

BATISTA, N.. Introdução Crítica ao Direito Penal Brasileiro. Rio de Janeiro: Revan, 1996.

CANOTILHO, J. G.. Direito Constitucional e Teoria da Constituição. $7^{a}$ edição, Coimbra: Almedina, 2000.

CARVALHO, M. D. L.. Fundamentação Constitucional do Direito Penal. Porto Alegre: Sergio Antonio Fabris Editor, 1992.

CEREZO MIR, J.. Curso de Derecho Penal Español. Madrid: Tecnos, 1997.

DOTTI, R. A.. Curso de Direito Penal - Parte Geral, 2a Edição. Rio de Janeiro: Forense, 2004.

FARIA COSTA, J. de; COSTA ANDRADE, M. da. Sobre a Concepção e os Princípios do Direito Penal Económico", In PODVAL, Roberto (org). Temas de Direito Penal Econômico, São Paulo: RT, 2001.

FELDENS, L.. Tutela Penal de Interesses Difusos e Crimes do Colarinho Branco: por uma relegitimação da atuação do ministério público: uma investigaçãoà luz dos valores constitucionais. Porto Alegre: Livraria do Advogado, 2002.

FIGUEIREDO DIAS, J. de. O Direito Penal entre a "Sociedade Industrial" e a "Sociedade do Risco". In: Revista Brasileira de Ciências Criminais, São Paulo, ano 9, n 33, p. 38-65, jan./mar. 2001.

FIGUEIREDO DIAS, J. de; COSTA ANDRADE, M. da. Problemática Geral das Infracções contra a Economia Nacional. In PODVAL, R.. Temas de Direito Penal Econômico. São Paulo: RT, 2001. 
GRECO, R.. Curso de Direito Penal - Parte Geral. $2^{a}$ edição. Rio de Janeiro: Impetus, 2003.

JESCHECK, H.-H.. Tratado de Derecho Penal. Trad. José Luis Manzanares Samaniego, 4ªd., Granada: Comares-Granada, 1993.

LUISI, L.. Os Princípios Constitucionais Penais. 2a edição. Porto Alegre: Sergio Antonio Fabris Editor, 2003.

SILVA, G. M. da. Direito Penal Português Parte Geral, I, Introdução e Teoria da Lei Penal, Vol. II, Lisboa: Verbo, 2010.

SUTHERLAND, E. E.. White Collar Crime. New York: The Dryden, 1949.

TIEDEMANN, K.. "La Ley Penal em Blanco: concepto y cuestiones conexas". In: Revista Brasileira de Ciências Criminais, vol. 37. São Paulo: RT, jan./mar. 2002.

TOLEDO, F. A.. Princípios Básicos de Direito Penal. São Paulo: Saraiva, 1994.

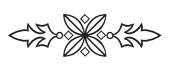

